\title{
Subjectivity in heterophenomenology
}

\author{
Gianfranco Soldati
}

Published online: 29 November 2006

(C) Springer Science + Business Media B.V. 2006

\begin{abstract}
I distinguish between naïve phenomenology and really existing phenomenology, a distinction that is too often ignored. As a consequence, the weaknesses inherent in naïve phenomenology are mistakenly attributed to phenomenology. I argue that the critics of naïve phenomenology have unwittingly adopted a number of precisely those weaknesses they wish to point out. More precisely, I shall argue that Dennett's criticism of the naïve or auto-phenomenological conception of subjectivity fails to provide a better understanding of the intended phenomenon.
\end{abstract}

Key words naïve phenomenology $\cdot$ Husserlian phenomenology $\cdot$ introspection · subjectivity $\cdot$ heterophenomenology

\section{Naïve phenomenology}

Consider a philosophical position, naïve phenomenology, described by the following set of claims.

Consciousness is subjective. It involves the first-person point of view. Because consciousness is subjective it cannot be studied from an objective, scientific and third-person point of view. Standard empirical science has no access to conscious experience. A proper study of consciousness requires a special methodology, one that studies consciousness from within, from the very subjective point of view from which it is experienced.

Knowledge in the first person about consciousness is based on introspection. Introspection is not accessible in the third-person and one is obliged to acknowledge an epistemic asymmetry between the first and the third-person. Whatever you may know about my conscious experience, my beliefs about such experience have authority over yours. In fact, introspective beliefs about seemings are infallible: however things actually are, I cannot be wrong about how they appear to me.

Conscious experiences are seemings. To have a colour experience means to experience how things visually appear to one. To sense pain means to have an

G. Soldati $(\bowtie)$

Department of Philosophy, University of Fribourg, Av. de l'Europe 20, 1700 Fribourg, Switzerland e-mail: gianfranco.soldati@unifr.ch 
experience of something appearing painful. There is no such thing as an experience of pain appearing painless. For something to be painful is not one among various ways a pain manifests itself, it is the experience of pain itself.

In so far as they are seemings, experiences are essentially qualitative, phenomenal. There is something 'it is like' to have an experience. This is not true for many other things that happen to us: there is nothing it is like to have one's own blood circulating through the brain, or one's backbone producing leucocytes, although our conscious life causally depends on those things happening and although preventing those things from happening would doubtless cause a whole series of conscious experiences.

The qualitative, phenomenal character of experience, its what-it-is-likeness, its 'seeming-like' character, presuppose the very possibility of a subjective view: for something to appear in a certain way, there must be a subject to whom things appear in that way; for an experience to deliver a certain way it is like to have it, a subject must exist for whom there is a way it is like to have that experience.

Finally, conscious experiences are subjective as they contain motivational and normative power. In so far as my action is conscious and intentional, it is controlled by subjective beliefs and desires: because I believe that I am responsible for the mess in the supermarket and that causing the mess was unintentional, I consequently stop my trolley and clear up the sugar I have been spilling all over the place. And it is in so far as I feel obliged to do the thing I am doing, that I can be said to behave according to certain rules.

\section{Naïve phenomenology and really existing phenomenology}

Naïve phenomenology, as I have described it so far, requires further elaboration. One may enquire whether the set of views presented under its heading yields a coherent philosophical position. It would be preposterous to attribute naïve phenomenology to Edmund Husserl, the founder of really existing phenomenology.

Consider, for instance, introspection. Husserl certainly thought, together with his teachers Wilhelm Wundt and Franz Brentano, that introspection plays a crucial role in our conception of what it means for something to be a conscious experience. ${ }^{1}$ This idea may reasonably be taken to imply that our canonical concept of imagination, say, is essentially related to the notion of one being able to know that one is imagining on the basis of mere introspection. ${ }^{2}$ Such a claim requires nothing else from introspection

\footnotetext{
${ }^{1}$ Cf. Wundt (1888: 304) and Brentano (1924: 128-29). In Ideas I Husserl writes: "It is evident that [...] consciousness and the content of consciousness are recognisable [erkennbar] only through [...] acts of reflection" (Husserl, 1913: 156-57). This passage leaves open the question as to whether one is able to acquire knowledge about consciousness only introspectively, or whether something qualifies as a conscious experience only if it can be accessed introspectively. Unless Husserl can be shown to require the first, much stronger reading, one should opt for the second.

${ }^{2}$ Many additional details would be needed in order to spell out the full nature of this requirement. For instance: what are the relations between the canonical definition given above and the possession conditions of one of the concepts under consideration? For a subject to possess a psychological concept is it necessary that he himself be able to apply it introspectively? One may wish to be liberal and to allow a subject to rely on somebody else's competence. Indeed, in the heyday of introspective psychology the application of specific psychological concepts was often thought to presuppose training and great concentration. That everybody should attain such a level of sophistication was not necessary. The linguistic division of labour was applied to psychological concepts.
} 
other than the fact that one can come to know that one imagines in a way one cannot come to know e.g., that one's blood is circulating in one's brain. Given the way we use it, our concept of blood circulating in our brain is not the concept of a conscious experience. This alone is far from committing us to the view that introspection provides a foundation for infallible knowledge or that introspection delivers the unique epistemic route to the study of consciousness.

Husserl surely believed it possible to acquire introspective knowledge of one's own conscious experiences. There is no reason, however, to suppose he took introspection to be infallible. No later than in the first edition of the Logical Investigations, Husserl objected to his teacher Brentano, who had argued that inner perception is infallible ("evident," as he put it), that inner and outer perceptions have "the same epistemological character" (Husserl, 1901: 703). "There is," he argues, "an acceptable distinction between evident and non-evident, between non-deceptive and deceptive perception [...], yet this distinction does not coincide with the former" (Husserl, 1901: 704). Indeed, Husserl thinks that "it is clear that most perceptions of mental states cannot be evident" (Husserl, 1901). In a previous passage of the same book he argued that "perception directed onto one's own experiences [...] in no way needs to be adequate" (Husserl, 1901: 333), where adequacy is a quality a perception earns when "it presents the object [...] such as it is."

Husserl's later conception of the role and status of introspection is heavily influenced by his adoption of transcendental philosophy. In Ideas I Husserl discusses at length the relation between phenomenology and "inner observation," concluding that one has to separate the difficulties related to the use of introspection in empirical psychology from those related to its function in phenomenology (cf. Husserl, 1913: $152 \mathrm{ff}$ ). Husserl is clearly aware that, from an empirical point of view, introspection cannot offer anything more than any other kind of inductive evidence. He thus argues that phenomenology does not use introspection as a form of evidence at all. In Ideas III he writes that "he who believes that whatever is accomplished by phenomenology has already been achieved in psychology by means of inner experience, speaks as wisely as he who maintains that one can obtain through physical observation [...] whatever the geometer may be able to offer to the physicist" (Husserl, 1971: 44).

Husserl's real point about the philosophical study of consciousness, no less than the philosophical study of anything is that, in such a study, no result should depend on any existential presupposition, whatever empirical basis the latter may have. There are at least two ideas at the root of this well-known doctrine. To begin with, there is the idea that a philosophical inquiry should aim at obtaining results concerning the specific essence of the items under scrutiny rather than the contingent conditions of their existence. In Ideas I Husserl writes that "a phenomenological doctrine of essences has as little need to be affected by the methods the phenomenologist would use in order to secure the existence of the experiences that provide the backing of his claims as geometry has to be concerned with the method that would secure the existence of the figures on the blackboard or the models in the cupboard" (Husserl, 1913: 153).

\footnotetext{
${ }^{3}$ It ought to be mentioned here that Brentano explicitly admitted the possibility for a subject to have false beliefs about her own experiences. Husserl's criticism fails to do full justice to this point in Brentano's theory. For more on Brentano's view see Soldati (2005).
} 
Whatever metaphysical status essences might finally be said to have ${ }^{4}$, in Husserl's view it is clear that those sciences concerned with essences ("eidetic sciences," as he called them), such as arithmetic, geometry, logic, and precisely philosophy, generate results that cannot be justified by appeal to empirical evidence (cf. Husserl, 1913: 20-21). This does not mean that experiences do not play an important role in our grasping of eidetic truths. Indeed, just as computer simulations can play a role in our understanding of the nature of multidimensional space, exercises in imagination may help us to better understand the concepts used in a philosophical theory of imagination.

In spite of its eidetic nature, the phenomenological study of consciousness should not be put on a par with formal sciences such as mathematical analysis or formal logic. "Transcendental phenomenology as a descriptive science of essences," Husserl says, "belongs to an entirely different set of eidetic sciences than the mathematical sciences" (Husserl, 1913: 142). The central reason behind this latter claim is that descriptive sciences, to which phenomenology is said to belong in spite of its transcendental approach, contain vague concepts that cannot reach the status of the "exact" concepts one finds in formal sciences. Whereas the exactness of such concepts are said to enable formal sciences to rely on deductive justification, descriptive eidetic sciences are required to search for other forms of priori warrant. ${ }^{5}$

Furthermore, there is the idea that philosophy is ultimately concerned with the disclosure of normative connections and that, in this respect, no empirical basis can suffice. Like Kant, Husserl is at pains to distinguish this suggestion from the more traditional claim that philosophy ought to establish necessary truths and that empirical findings suffice to establish exclusively contingent truths. Hence, for example, Husserl would argue that a philosophical theory of intentional consciousness aims at clarifying the relation between experience and content in a way that determines the features an experience must have in order to be poised for the acquisition of knowledge. Which features of a judgement, for instance, are required for such experience to convey access to a truth-valuable content? Can a perceptual experience, given its nature, satisfy these requirements? ${ }^{6}$

This is obviously not the place to defend Husserl's conception of philosophy, containing, as it does, many aspects ranging from the very idea of philosophy as a discipline delivering a priori justification to the metaphysical doctrine of essences. It is also clear that, unlike a number of other influential philosophers of the twentieth century, Husserl did not question the very possibility of introspective knowledge. There are, however, pervasive systematic reasons in Husserlian phenomenology that

\footnotetext{
${ }^{4}$ The relevant question here concerns the relation between essences and other types of entities. Husserl appears to have thought that the answer to this question must take into consideration the different ontological regions into which reality divides. The relation between the number two and a heap of two apples is not the same as the relation between the essence of an intentional act and an occurring perception. Essences, one may wish to say, do not manifest themselves in the same way in all regions of reality.

${ }^{5}$ Husserl's inquiries into the nature of "categorial intuition" and Wesensschau are partially born out of this need.

${ }^{6}$ Useless to say that more would be needed in order to secure Husserl's claim that the issues at stake are indeed normative. As it has often been noticed, there is a very weak form of 'ought' in the claim that an experience ought to be such and such in order to be poised for the grasp of truth-conditions. Husserl was aware of this, and he explicitly dealt with the different kinds of ought on different occasions (for instance in the Prolegonema to the Logical Investigations).
} 
warn against considering introspective knowledge as enjoying a privileged position over and against any other form of empirical knowledge. From a phenomenological point of view the issue does not so much concern the question of what one can learn about consciousness on the basis of an introspective inquiry, but rather the results one may obtain by a philosophical reflection on concepts typically applied in the firstperson on the basis of introspection. The presumption that philosophical inquiry itself ought to rest on introspective evidence would be seriously flawed.

Similar considerations apply to other facets of naïve phenomenology. It is, indeed, daunting to observe that the distinction between naïve phenomenology and really existing phenomenology is all too often ignored. As a consequence, the weaknesses inherent in naïve phenomenology are, as such, attributed to phenomenology. To show the various ways in which real existing phenomenology ought to be distinguished from naïve phenomenology would go beyond the limits of this paper. The task I have set myself in the following has a more modest objective. I argue that the critics of naïve phenomenology have unwittingly adopted a number of precisely those weaknesses they wish to point out. More precisely, I shall argue that Dennett's criticism of the naïve or auto-phenomenological conception of subjectivity fails to provide a better understanding of the intended phenomenon.

\section{Subjectivity and consciousness}

Experiences, the naïve phenomenologist argues, are subjective. Daniel Dennett has repeatedly submitted that heterophenomenology, the scientific, third personal, objective alternative to 'autophenomenology,' is 'the sound way to take the firstperson point of view as seriously as it can be taken" (Dennett, 2003: 1). He writes:

[...] I described a method, heterophenomenology, which was explicitly designed to be "the path leading from objective physical science and its insistence on the third-person point of view, to a method of phenomenological description that can (in principle) do justice to the most private and ineffable subjective experiences, while never abandoning the methodological principles of science" (Dennett, 2001 quoting Dennett, 1991: 72).

A full understanding of Dennett's proposal presupposes a precise grasp of what he means when he says that experiences are subjective. This can only be a first, albeit important step in the evaluation of the heterophenomenologist's ambition to do justice to "the most private and ineffable subjective experiences."

In discussing David Chalmers views, Daniel Dennett makes the following claim:

I don't stipulate at the beginning of the day that our subjective beliefs about our first-person experiences are "phenomenological" beliefs in a sense that requires them somehow to depend on (but not causally depend on) experiences that zombies don't have! I just stipulate that the contents of those beliefs exhaustively constitute each person's (or zombie's) subjectivity. (Dennett, 2001) ${ }^{7}$

\footnotetext{
${ }^{7}$ See also: "You reserve judgment about whether the subject's beliefs, as expressed in their communication, are true, or even well-grounded, but then you treat them as constitutive of that subject's subjectivity" (Dennett, 2003: 4).
} 
Following this stipulation, the subjectivity of an experience would be constituted by the beliefs the subject has about it.

As a mere stipulation, the claim under scrutiny is tantalizing. One may indeed wonder whether it is a consequence of a general metaphysical doctrine. Such a doctrine, 'radical idealism,' would encompass the claim that the phenomenon of electricity, say, is exhaustively constituted by the content of one's (whose?) beliefs about electricity. Although not unheard of, the position is radical. Yet apart from its radicalism, the position would not help to explain why conscious experiences, as opposed to electricity, are subjective. One ought to assume that Dennett's stipulation does not stem from radical idealism. The stipulation has to be motivated by specific considerations pertaining either to the nature of experiences or to the status of beliefs about them or to some feature concerning the relation between them. Let us then look more precisely at these different possibilities.

Joseph Levine has remarked that a theory about conscious experience ought to take "the conscious experiences themselves, not merely our verbal judgments about them as the primary data to which a theory must answer" (Levine, 1994, quoted in Dennett, 2001 and in Dennett, 2003). The requirement sounds reasonable: it is analogous to the complaint that a theory about electricity should not take beliefs about it as its primary data. Similarly, Alvin Goldman contends that when a blindsighted subject reports that he does not see the thing in front of him, it is the fact that he does not see the thing that interests the cognitive scientist, not the fact that the subject believes that he does not see it (Goldman quoted by Dennett, 2001).

Yet Dennett does not agree. Beliefs about one's experiences, he thinks, can be both positive and false negative. I can attribute to myself an experience I have not had and I can fail to attribute an experience I have. Given this fact, Dennett argues, one should not take the subject's reports at face value. One should remain neutral about the truth of the subject's beliefs and, instead, opt for an explanation of their very occurrence. What needs to be explained, Dennett urges, is not the experience but the beliefs about the experience.

It has been noticed (cf. Goldman's reply in Dennett, 2001) that it would be odd to conclude that one should refrain from taking first-person beliefs at face value based on the fact that they happen to be false. Our knowledge of the external world is largely based on perception, which is known to generate experiences that are both false positive and false negative. Yet one does not consider the fact that perception is fallible as a ground for remaining neutral with respect to what it delivers. So why should our attitude be any different with respect to introspective first-person beliefs?

Dennett's point might be less epistemological than metaphysical. He might be insisting on the independence of a belief concerning one's experience from the experience itself. Discussing well-known results with respect to masked semantic priming, Dennett considers the possibility of a theory determining whether subjects are, in fact, conscious of the priming stimulus, but then forget it as a consequence of the mask. Dennett argues that when subjects are taught the theory they "would learn for the first time that they were, or were not, conscious of those stimuli" (Dennett, 2003: 9). This would show that it is possible for a subject to have a conscious experience and yet not to believe, not even be disposed to believe that she does. If conscious experiences are seemings, as the naïve phenomenologist would have it, then it ought to be possible that something seems to a subject in a certain way 
although the subject does not believe it and vice versa. Although something seems $F$ to the subject, the subject might not believe that something seems $F$ to her and although the subject believes that something seems $F$ to her, nothing might in fact seem $F$ to her. Stated in this way the claim is purely metaphysical: it says nothing about the trust-worthiness of first-person beliefs.

It sounds at times as if the result obtained above would stand at odds with some other things Dennett has been saying, and has repeatedly quoted himself as saying:

You are not authoritative about what is happening in you, but only about what seems to be happening in you, and we are giving you total, dictatorial authority over the account of how it seems to you [...]. (Dennett, 1991: 96-97; Dennett, 2003: 4).

If experiences are seemings, then what is said in this quotation would imply that the subject has privileged epistemic access to his own experiences. The quotation would rule out the possibility of one having such a privilege with respect to other things happening 'in' the subject, such as the circulating of blood in one's brain. This, we saw, is precisely the naïve phenomenologist's view.

There is an obvious danger of a terminological confusion at this stage. Consider the debate about mental imagery. Subjects typically report that they rotate the object in their imagination. Pylyshyn and others have argued that there are competing alternatives about the subject's actual cognitive performance. Suppose the subject utters:

(1) It seems to me that I am rotating the object in imagination.

Should we consider the subject to be authoritative with respect to what is stated with utterance (1)? It all depends on how 'it seems to me that...' is interpreted. At least two possibilities are available. Utterance (1) might be taken to be equivalent either to:

(1a) I have the experience of rotating the object in imagination, or to:

(1b) I believe that I am rotating the object in imagination.

This latter interpretation is warranted by locutions such as 'it seems to me that the Olympics will take place in London' or 'it seems to me that Brutus killed Caesar in Rome in front of the theatre,' where readings along (1b) are preferred to readings along (1a).

If we grant, following Dennett's appeal, the possibility that the subject mistakenly reports to be rotating the object in imagination, then (1a) might be false. The subject cannot be granted any special authority over it.

Utterance (1b) itself can be read in different ways. On one possible reading, it simply reinforces the belief the subject would have expressed by uttering 'I am rotating the object in imagination.' In that case, where (1b) expresses a belief, the subject might indeed be said to have authority over it, in the specific sense that, given (1b), and supposing that the subject is sincere and not simulating, it makes no sense to doubt that the subject really has the belief she is expressing, the belief that she is rotating an object in imagination.

This view ultimately boils down to the classical distinction between describing and expressing. The point could have been formulated without any appeal to 'seeming' at all. It would suffice to state that when the subject utters 'I am rotating the object in imagination' she describes her experience and expresses her belief. The subject has no authority over what she describes, but she has authority, a special kind of authority, over what she expresses. It ought to be pointed out that if the former 
kind of authority, the one we are asked to sacrifice, would have had real epistemic import, the epistemic status of the second one, the one that is retained, is much more doubtful. Indeed, where it is clear that one can come to know something by describing it, it is much less obvious that one can come to know something by expressing it. ${ }^{8}$ Independently of this issue, however, the expressing relation does not concern the independence claim under consideration: even if the subject were granted authority over what he expresses, the beliefs describing the experience could still be independent of the latter.

I said that (1b) could be read in at least one other way. It may be read as a description not of the original experience, but of a belief about it. Utterance (1) would then be the expression of the subject's second order belief that she believes first order - to have the experience of rotating an object in imagination. At this stage the argument might be that the subject is endowed with 'dictatorial authority' over that sort of first order belief, as opposed to her own experience. We would be asked to grant the subject infallible knowledge about her own beliefs, as opposed to her knowledge about her own experiences. The claim would merit further discussion since it appears to presuppose an important distinction between experiences and beliefs (does it not seem to me that I believe that all men are equal in front of the law?). For the issue at stake, however, the question is irrelevant. Again, the independence claim under consideration concerns the relation between experience and first order belief, not between first order and second order belief. With respect to the issue at stake, then, Dennett's 'dictatorial authority' would be once more irrelevant.

Thus, so far, little if anything has been shown that conflicts with Dennett's approval of the independence claim. With respect to subjectivity, the independence claim generates the following alternative: either an experience is subjective, independent of whether or not there is a belief about it, or it is not. If it is, then the constitution claim must go: if an experience is subjective independent of what the subject believes about it, then its subjectivity cannot be the result of the subject having a belief about it. But then one cannot maintain that the subjectivity of experiences can be reduced to, or be fully accounted for in terms of, the subject's beliefs about them.

If, on the other hand, one endeavors to save the constitution claim, if one wishes to maintain that an experience is not subjective unless there is a belief about it, then the independence claim can only be satisfied at the price of letting subjectivity be a variable feature of experience. Subjective, then, are those experiences that are only the object of a belief. An immediate objection would insist on the fact that if not by virtue of being objects of beliefs, experiences are subjective by virtue of some other, possibly intrinsic feature, such as the fact that they are seemings. Let us ignore this objection for the moment - it will reappear later. Let us assume that subjectivity is a feature some experiences acquire by virtue of there being a belief about them. The question must still be answered as to which features of those beliefs, or of the experiences the beliefs are about, are responsible for the attribution of subjectivity. As we have already seen, states of affairs in general do not become subjective

\footnotetext{
${ }^{8}$ It ought to be noted here that Brentano's famous notion of inner perception comes close to the idea that there is 'knowledge by expression.' See Soldati (2005).
} 
merely by virtue of the subject having a belief about them. Additional restrictions are needed.

One first restriction would concern the states of affairs the belief is about. Subjectivity, one might argue, emerges when the belief is about a state of affairs that contains the subject, or depends metaphysically on the subject. So, my belief that the stone falls does not make the stone's fall subjective, but my belief that I have a pain makes my pain subjective in so far as I, as a subject, am part of the state of affairs that contains pain. This view presupposes that one can determine what a subject is independently of one's account of what makes an experience subjective. It might be felt that this puts too much of a burden on a possible theory concerning the status of subjects. There is another reason, however, that makes the view even more unpalatable. This is because it allows for an experience to be subjective merely by virtue of there being somebody having a belief about it. Your pain would become subjective by virtue of me having a belief about it. In order to prevent such an odd conclusion, a second restriction would require that the subject be both constituent of the state of affairs and believer. My pain is subjective because I have a belief about it. This is better, but not fully convincing. Consider, for instance, the subject's first personal belief that she herself weights $60 \mathrm{~kg}$. Both restrictions are satisfied but is one prepared to say that the subject's weight constitutes a subjective state of affairs?

This last conclusion could, of course, be avoided if one were ready to accept the idea that a state being subjective depends on some of its non-physical intrinsic properties. One might thus require that the state of affairs the subject has a belief about contain both the subject himself and one of his mental properties. The subject's belief should concern his own mental states. At this stage, the questions we neglected earlier become pressing. If a state can be mental before its bearer has a belief about it, why then can't it be subjective under those same conditions? And if a state about which a subject has a belief is not subjective unless it is mental, why is it the subject's belief about it, rather than its intrinsic mentality, that makes it subjective?

What, however, would be the consequences of not adopting this last requirement? What if one were prepared to say that any state of affairs containing the subject becomes subjective as soon as the subject himself has a belief about it? It appears that one would then severe the connection between consciousness and subjectivity so much that not only would there be non-subjective experiences - because there is no belief about them - but also subjective states of affairs that are not conscious experiences. Arguments might be found that speak in favor of such a radically antiCartesian move. It is doubtful, however, that such arguments can be made available to Dennett's line of thought. For an account of subjectivity would then fall short of providing any specific information about the nature of conscious experiences. The study of subjectivity would be independent of the study of consciousness. And so neither auto-, nor hetero-, nor naïve phenomenology would be particularly suited for an understanding of subjectivity.

\section{Naïve phenomenology and heterophenomenology}

Although it contains claims that merit elaboration, naïve phenomenology as such does not really warrant refutation. By criticizing naïve phenomenology one rather 
faces the danger of inheriting some of its weaknesses. One such weakness lies in the way naïve phenomenology establishes the relation between consciousness and subjectivity. We are led to think that conscious experiences are subjective in so far as the subject has a privileged epistemic access to them. When asked to specify the intended privilege, the naïve phenomenologist typically appeals to introspection and to its putative infallibility. Once the claim of infallibility has been shown not to hold, the privilege disappears and the subjectivity of the experience remains unaccounted for.

Dennett's heterophenomenologist rejects the infallibility claim. But he appears to hold on the idea that the subjectivity of an experience is somehow connected to the access the subject has to it. We have seen that even without infallibility, the idea is not suited to provide a coherent account of the subjectivity of experiences.

Acknowledgment I wish to thank Edi Marbach and one anonymous referee for useful discussion and helpful comments. I thank Justin Morris for the linguistic revision of this article.

\section{References}

Brentano, F. (1924). Psychologie vom Empirischen Standpunkt, Bd. 1. Herausgegeben von Oskar Kraus. Hamburg: Meiner.

Dennett, D. (1991). Consciousness Explained. Boston: Little Brown.

Dennett, D. (2001). The fantasy of first-person science. Third Draft. March 1, 2001. http://ase.tufts.edu/ cogstud/papers/chalmersdeb3dft.htm).

Dennett, D. (2003). Who's on first? Heterophenomenology explained. Journal of Consciousness Studies, 10(9-10), 19-30.

Husserl, E. (1901). Logische Untersuchungen (I-VI), Band II. Halle: Niemeyer.

Husserl, E. (1913). Ideen zu einer reinen Phänomenologie und phänomenologischen Philosophie. Halle a. d. Saale: Niemeyer. (Reprinted in: Husserliana Vol III/1, quoted following pagination in Husserliana).

Husserl, E. (1971). Ideen zu einer reinen Phänomenologie und phänomenologischen Philosophie. Drittes Buch: Die Phänomenologie und die Fundamente der Wissenschaften. Den Haag: Martinus Nijhoff.

Levine, J. (1994). Out of the closet: A qualophile confronts qualophobia. Philosophical Topics, 22, 107126.

Soldati, G. (2005). Brentano on inner perception, intrinsic truth and evidence. In M. E. Reicher \& J. C. Marek (Eds.), Experience and Analysis (pp. 63-73). Wien.

Wundt, W. (1888). Selbstbeobachtung und innere Wahrnehmung. Philosophische Studien, 4, 292-309. 